Tohoku J. Exp. Med., 2006, 209, 61-67

Case Report

\title{
Successful Autologous Peripheral Blood Stem Cell Transplantation Using Thiotepa in a Patient with Systemic Sclerosis and Cardiac Involvement
}

\author{
Atsushi Komatsuda, Yoshinari Kawabata, Takahito Horiuchi, \\ Mutsuhito Motegi, Masatoyo Ozawa, Naohito Fujishima, Masaaki Kume, \\ Makoto Hirokawa, Hideki Wakui, Akihiko Yamaguchi ${ }^{1}$ and Ken-IChi Sawada \\ Third Department of Internal Medicine, Akita University School of Medicine, \\ Akita, Japan, and \\ ${ }^{I}$ Department of Internal Medicine, Senboku General Hospital, Akita, Japan
}

\begin{abstract}
Komatsuda, A., Kawabata, Y., Horiuchi, T., Motegi, M., Ozawa, M, Fujishima, N., Kume, M., Hirokawa, M., Wakui, H., Sawada, K. and Yamaguchi, A. Successful Autologous Peripheral Blood Stem Cell Transplantation Using Thiotepa in a Patient with Systemic Sclerosis and Cardiac Involvement. Tohoku J. Exp. Med., 2006, 209 (1), 61-67 — A 19-year-old man with systemic sclerosis (SSc) was hospitalized for autologous peripheral blood stem cell transplantation (auto-PBSCT) due to progressive scleroderma and cardiac involvement despite conventional treatment. During the administration of cyclophosphamide $\left(60 \mathrm{mg} / \mathrm{kg} /\right.$ day for 2 days) for mobilization and collection of CD34 ${ }^{+}$ selected peripheral blood stem cells, he developed congestive heart failure. Echocardiogram showed hypokinetic asynergy from the septum to posterior wall, which might indicate underlying cardiac damage. We were also concerned about the risk of high-dose cyclophosphamide-induced cardiotoxicity. Since the dose-limiting toxicity of thiotepa, an alkylating agent, is myelosuppression, and cardiac toxicity due to thiotepa is less common, we used a conditioning regimen consisting of thiotepa $(10 \mathrm{mg} / \mathrm{kg} / \mathrm{day}$, day -5$)$ and lowdose cyclophosphamide ( $50 \mathrm{mg} / \mathrm{kg} /$ day, days -3 and -2 ), instead of the conventional highdose cyclophosphamide $(50 \mathrm{mg} / \mathrm{kg} / \mathrm{day} \times 4$ days/course $)$. The post-transplant course was uneventful, and the modified Rodnan skin thickness score improved from 32 to 15 . The present case report demonstrates that thiotepa can be employed as a conditioning regimen for auto-PBSCT in SSc patients with cardiac involvement in order to reduce cyclophosphamide-induced cardiotoxicity. — autologous peripheral blood stem cell transplantation (PBSCT); cardiotoxicity; cyclophosphamide; systemic sclerosis; thiotepa

(C) 2006 Tohoku University Medical Press
\end{abstract}

Systemic sclerosis $(\mathrm{SSc})$ is a generalized disease of the small arteries, microvessels, and diffuse connective tissue, characterized by exten- sive fibrosis and vascular obliteration in the skin and visceral organs including the gastrointestinal tract, lungs, heart, and kidneys. Although the eti-

Received January 19, 2006; revision accepted for publication March 3, 2006.

Correspondence: Atsushi Komatsuda, M.D., Third Department of Internal Medicine, Akita University School

of Medicine, 1-1-1 Hondo, Akita City, Akita 010-8543, Japan.

e-mail: komatsud@med.akita-u.ac.jp 
ology of SSc remains unknown, this disease is characterized by predominant T-cell activation, production of autoantibodies to Scleroderma-70 (Scl-70) (anti-topoisomerase I) and cytokine release (Sakkas and Platsoucas 2004).

Recent studies in a large series of patients with SSc demonstrated that the prognosis is associated with the extent of skin involvement and/or affected visceral organs (Ferri et al. 2002; Scussel-Lonzetti et al. 2002). Significantly worse prognosis was observed in the diffuse cutaneous subset, in male gender, and in patients with lung, heart, and renal involvement (Ferri et al. 2002). Standardized mortality ratios were $2.71,2.76$, and 6.17 in the limited, intermediate, and diffuse subsets, respectively (Scussel-Lonzetti et al. 2002). Although cyclophosphamide has documented but limited efficacy in patients with SSc and alveolitis (White et al. 2000), effective treatment has not been found to prevent disease progression in SSc.

Autologous transplantation of $\mathrm{CD} 34^{+}$selected cells after high-dose chemotherapy has recently emerged for patients with a variety of diseases, including hematological diseases, solid tumors, and immunological diseases resistant to conventional therapy (Kawabata et al. 2003). CD34 ${ }^{+}$ selected autologous peripheral blood stem cell transplantation (PBSCT) has been initiated as a promising new therapy for patients with refractory diffuse SSc with early visceral organ involvement in the United States and Europe since the 1990's (McSweeney et al. 2002; Farge et al. 2002, 2004). Improvement of the disease was observed in the majority of patients after PBSCT, although there were some deaths related to either the PBSCT procedure or disease progression; the projected 2 -year and 5-year survival rates were $79 \%$ and $72 \%$, respectively (McSweeney et al. 2002; Farge et al. 2004). In most SSc patients or patients with other diseases, high-dose cyclophosphamide was introduced in mobilization and conditioning regimens for PBSCT (Itoh et al. 2004; Sacchardi et al. 2004; Tang et al. 2004). It is well known that high-dose cyclophosphamide can cause an acute form of cardiotoxicity within 10 days of administration (Gharib and Burnett 2002). Furthermore, cardiovascular manifestations including pericardi- al disease, myocardial disease, and arrhythmias frequently occur in patients with SSc (Janosik et al. 1989). In general, eligibility criteria for PBSCT require preserved cardiac function, defined as left ventricular ejection fraction (LVEF) more than 50\% (Nishio et al. 2001; Itoh et al. 2004; Tang et al. 2004). However, patients with SSc or other diseases complicated by cardiac dysfunction will have significantly increased treatment-related mortality. Therefore, when such patients receive autologous PBSCT (auto-PBSCT) using high-dose cyclophosphamide, we need to pay close attention to its cardiotoxicity (Saccardi et al. 2004).

Here we report a patient with progressive and refractory SSc, who received successful $\mathrm{CD} 4^{+}$cell-selected auto-PBSCT using conditioning regimens incorporating thiotepa to reduce high-dose cyclophosphamide-induced cardiotoxicity.

\section{Case Report}

A 19-year-old man was admitted to Akita University Hospital on November 17, 2003 to receive auto-PBSCT. He had a history of bilateral hand edema and elbow joint pain from December 2000, and Raynaud's phenomenon from February 2001. He was diagnosed with SSc at Senboku General Hospital, based on skin manifestations (Raynaud's phenomenon, bilateral sclerodactyly, proximal scleroderma, and bilateral hand edema) (Subcommittee for scleroderma criteria of the American Rheumatism Association Diagnostic and Therapeutic Criteria Committee 1980) and the presence of anti-nuclear antibodies and antiScl-70 antibodies. He was treated with prednisolone (PSL) (10 mg/day) and cilostazol (200 mg/ day) from June 2001. From August 2001, he developed polyarthralgia and showed progression of scleroderma including the face, neck and trunk. From October 2001, he was treated with $30 \mathrm{mg} /$ day PSL for weeks. Treatment was partially effective for polyarthralgia, but skin symptoms became progressive with a tapering course. He demonstrated bilateral fingertip ulcers and limitation of both fist closure and finger extension.

On admission, height was $170 \mathrm{~cm}$, weight 
$49.9 \mathrm{~kg}$, body temperature $36.5^{\circ} \mathrm{C}$, pulse rate 100 beats/min, respiratory rate 16 breaths/min, and blood pressure 108/54 mmHg. Physical examination demonstrated bilateral sclerodactyly and proximal scleroderma, face, neck, and trunk. Modified Rodnan skin thickness score (mRSS) (Clements et al. 1993) was 32. The lungs and heart were normal. The liver and spleen were not palpable. Bowel sounds were normal.

The erythrocyte count was $513 \times 10^{4} / \mu 1$, hemoglobin $14.2 \mathrm{~g} / \mathrm{dl}$, hematocrit $43.2 \%$, leukocyte count $7,100 / \mu 1$ (neutrophils $74 \%$, monocytes $6 \%$, and lymphocytes $20 \%$ ), and platelet count $296 \times 10^{3} / \mu 1$. Urinalysis gave normal results. The serum total protein was $7.3 \mathrm{~g} / \mathrm{dl}$, albumin 3.8 $\mathrm{g} / \mathrm{dl}$, blood urea nitrogen $8.0 \mathrm{mg} / \mathrm{dl}$, and creatinine $0.6 \mathrm{mg} / \mathrm{dl}$. Human atrial natriuretic peptide was $18.0 \mathrm{pg} / \mathrm{ml}$ (normal range: less than $40.0 \mathrm{pg} / \mathrm{ml}$ ) and brain natriuretic peptide (BNP) was $50.5 \mathrm{pg} /$ $\mathrm{ml}$ (normal range: less than $18.4 \mathrm{pg} / \mathrm{ml}$ ). Thyroid function tests were normal. C-reactive protein was $1.8 \mathrm{mg} / \mathrm{dl}$. Serological study indicated the presence of anti-nuclear antibodies with a speckled pattern (2,560-fold), anti-Scl-70 antibodies (169.4 IU/ml), anti-double-stranded (ds) DNA antibodies (63.6 IU/ml), and anti-ribonucleoprotein (RNP) antibodies (52.5 IU/ml). Serum CH50 was $23 \mathrm{U} / \mathrm{ml}, \mathrm{C} 342 \mathrm{mg} / \mathrm{dl}$, and C4 $8 \mathrm{mg} / \mathrm{dl}$. Circulating immune complexes (IC) measured by the $\mathrm{C} 1 \mathrm{q}$ binding assay were $7.4 \mu \mathrm{g} / \mathrm{ml}$ (less than $3.0 \mu \mathrm{g} / \mathrm{ml})$. Although high titers of anti-ds DNA antibodies, anti-RNP antibodies and IC, and hypocomplementemia were observed, he had no clinical features associated with systemic lupus erythematosus or vasculitis.

Chest radiograph did not show either cardiomegaly or reticular shadow in the lung fields. Electrocardiogram demonstrated sinus tachycardia with low QRS voltage. Myocardial scintigraphy was not performed. Pulmonary function test demonstrated normal results of forced expiratory volume in one second $(100.4 \%)$ and \% diffusing capacity for carbon monoxide $(94.5 \%)$, but a slight reduction of \% vital capacity $(71.2 \%)$. Examination of the upper esophago-gastrointestinal tract demonstrated normal motility.

Based on rapidly progressive skin involvement and mild cardiac involvement despite continuing treatment, we considered his prognosis very poor. We also judged this patient eligible for auto-PBSCT (Burt et al. 2003; Farge et al. 2002; McSweeney et al. 2002). The protocol for autoPBSCT in this patient was approved by the ethics committee of Akita University Hospital. Written

\section{Clinical course I}

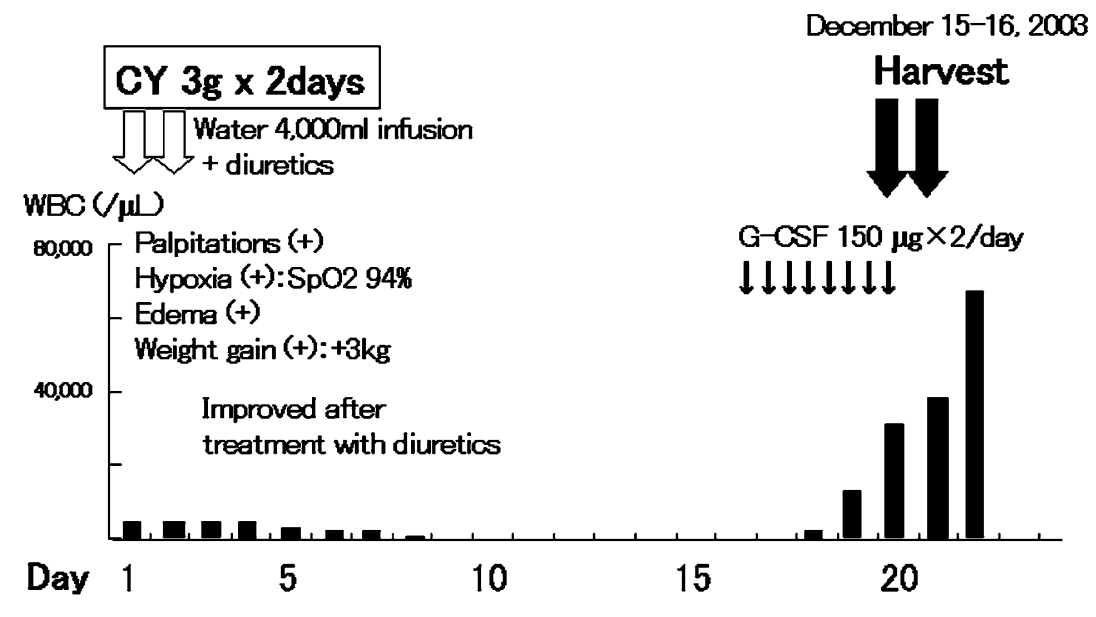

Fig. 1. Clinical course of the patient (I). During mobilization, the patient received high-dose cyclophosphamide (60 mg/kg/day for 2 days). Thereafter, he developed congestive heart failure, but his condition improved after treatment with furosemide. CY, cyclophosphamide; G-CSF, granulocyte-colony stimulating factor; WBC, white blood cell count. 


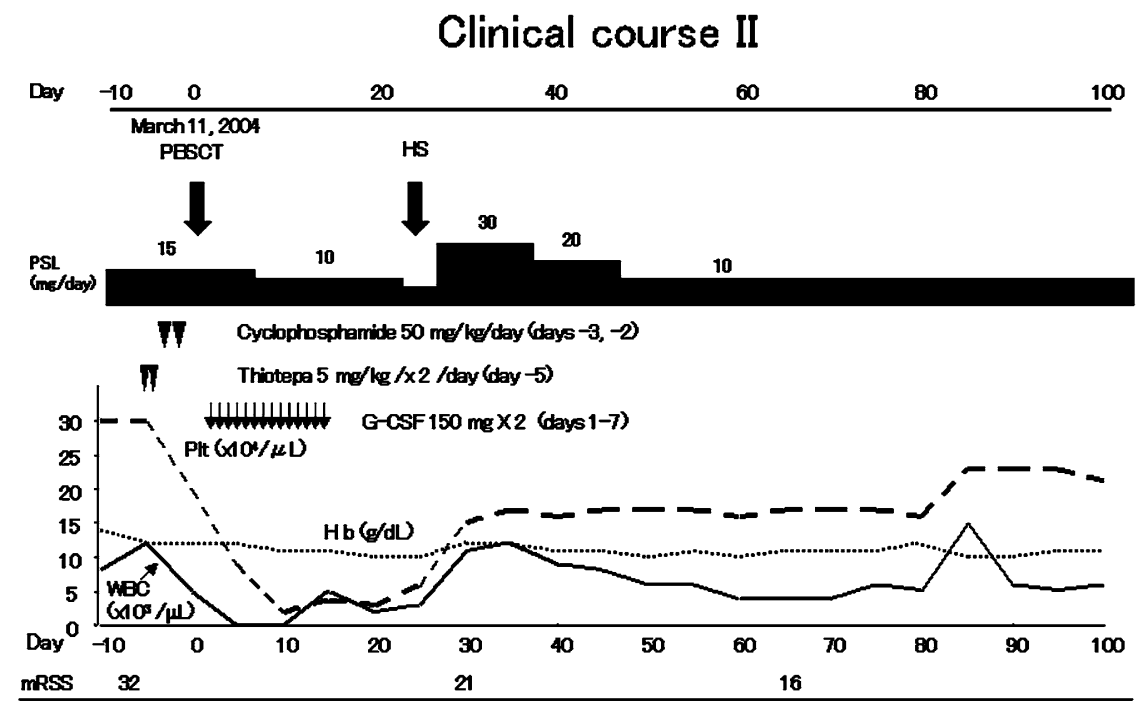

Fig. 2. Clinical course of the patient (II). During conditioning, the patient did not develop congestive heart failure, and he was successfully treated with autologous PBSCT. G-CSF, granulocyte-colony stimulating factor; $\mathrm{Hb}$, hemoglobin; HS, hemophagocytic syndrome; mRSS, modified Rodnan Skin Score; PBSCT, peripheral blood stem cell transplantation; Plt, platelet count; PSL, prednisolone WBC; white blood cell count.

informed consent was obtained. The clinical course is shown in Figs. 1 and 2. Mobilization and collection of peripheral blood stem cells (PBSCs) were achieved with a conventional priming regimen in combination with granulocytecolony stimulating factor (G-CSF) (Farge et al. 2004). The patient received high-dose cyclophosphamide $(60 \mathrm{mg} / \mathrm{kg} /$ day for 2 days). Thereafter, he developed palpitations, mild hypoxemia (oxygen saturation $\left[\mathrm{SpO}_{2}\right]$ : 94\%), edema, and body weight gain $(3 \mathrm{~kg})$. At that time, the total volume of intake was about $4,000 \mathrm{ml}$, and output about $1,600 \mathrm{ml}$. Electrocardiogram demonstrated sinus tachycardia (120 beats/min) with low QRS voltage. Echocardiogram showed focal hypokinetic asynergy from the septum to posterior wall, mild pericardial effusion, and a normal LVEF $(75 \%)$. He was treated with furosemide intravenously, and his condition improved. After administration of G-CSF (300 $\mu \mathrm{g} /$ day for 5 days), $23 \times 10^{6}$ $\mathrm{CD} 34^{+}$cells $/ \mathrm{kg}$ were harvested over two consecutive days, and $8.1 \times 10^{6} \mathrm{CD} 34^{+}$cells $/ \mathrm{kg}$ with a purity of $96 \%$ were positively selected using CliniMacs (Miltenyi Biotec GmbH, Bergisch, Gladbach, Germany).
We considered that the patient developed congestive heart failure (CHF) due to cardiac involvement of SSc. We were also concerned about the risk of high-dose cyclophosphamide-induced cardiotoxicity. As the conditioning regimen for this patient, we administered thiotepa (two doses of $5 \mathrm{mg} / \mathrm{kg}$ on day -5) and low-dose cyclophosphamide $(50 \mathrm{mg} / \mathrm{kg} /$ day on days -3 and -2 ) (Aversa et al. 1999). During conditioning, the patient did not develop CHF recurrence. Purified CD34 ${ }^{+}$ selected PBSCs were infused on day 0 (March 11, 2004). On day 13, the erythrocyte count was 418 $\times 10^{4} / \mu 1$, hemoglobin $10.9 \mathrm{~g} / \mathrm{dl}$, hematocrit $33.4 \%$, leukocyte count $7,600 / \mu 1$ (neutrophils $46 \%$, monocytes $13 \%$, lymphocytes $4 \%$, myelocytes $14 \%$, and metamyelocytes $23 \%$ ), and platelet count $42 \times 10^{3} / \mu 1$. On day 22 , he was suspected of virus-associated hemophagocytic syndrome, although pathogenic virus was not detected. $\mathrm{He}$ was treated with PSL (30 mg/day) and intravenous IgG (5 g/day) and his condition improved thereafter. Two months after PBSCT, rapid improvement in scleroderma was observed; the mRSS decreased from 32 to 16 . In December 2005, the mRSS further decreased 15. A serologi- 
cal study showed decreased serum titers of antiScl-70 antibodies (40 IU/ml), anti-ds DNA antibodies (less than $2 \mathrm{IU} / \mathrm{ml}$ ), and anti-RNP antibodies $(16 \mathrm{IU} / \mathrm{ml})$, and normal serum levels of CH50 (43 U/ml), C3 (115 mg/dl), and C4 (22.6 $\mathrm{mg} / \mathrm{dl})$. A pulmonary function test also showed improvement in \% vital capacity (82.3\%). BNP normalized to $6.4 \mathrm{pg} / \mathrm{ml}$.

\section{Discussion}

Primary cardiovascular manifestations of SSc include pericardial disease, myocardial disease, conduction abnormalities, and cardiac arrhythmias (Janosik et al. 1989). In our patient, pre-transplant chest radiograph did not show any abnormal findings, but electrocardiogram demonstrated sinus tachycardia and low QRS voltage, and the BNP level was high. These findings indicated that the patient might have developed cardiac damage due to SSc.

Since adverse prognostic factors have been reported to include male gender (Ferri et al. 2002), diffuse cutaneous SSc, visceral involvement such as heart (Ferri et al. 2002; Ioannidis et al. 2002; Scussel-Lonzetti et al. 2002), and the presence of anti-Scl-70 antibodies (Ioannidis et al. 2002), we considered that our patient would have a very poor prognosis, and was eligible for autoPBSCT.

We used cyclophosphamide (two daily successive injections of $3,000 \mathrm{mg}$ [60 mg/kg/day]) as employed in the priming regimen in the European Group for Blood and Marrow Transplantation/ European League Against Rheumatism (EBMT/ EULAR) registry (Farge et al. 2004). Although the regimen has been successfully used in many patients with more severe myocardial dysfunction than that in our patient, he developed CHF. Since urine volume at mobilization was less than the total volume of intake resulting in $3 \mathrm{~kg}$ weight gain, and CHF improved promptly after intravenous injection of diuretics, CHF might have been caused by the overhydration.

In autologous or allogeneic PBSCT, highdose cyclophosphamide is widely used for both mobilization and conditioning regimens (Fujimaki et al. 2001; Nishio et al. 2001; Itoh et al. 2004;
Sacchardi et al. 2004; Tang et al. 2004). However, high-dose cyclophosphamide can cause an acute form of cardiotoxicity within 10 days of administration, and that a total dose of more than 170-180 $\mathrm{mg} / \mathrm{kg}$ per course (over 4-7 days) is the risk factor (Gharib and Burnett 2002). Therefore, we are concerned about that patients with cardiac impairment are eligible for PBSCT. An LVEF less than $50 \%$ has generally been considered a contraindication for stem cell transplantation (SCT) (Itoh et al. 2004; Tang et al. 2004). However, there are no reports demonstrating the absolute level of cardiac dysfunction that rules out SCT (Itoh et al. 2004). Tang et al. (2004) described that patients with malignant lymphoma complicated by an LVEF less than $50 \%$ could safety receive auto-PBSCT, although all patients received a conditioning regimen (cyclophosphamide $120 \mathrm{mg} / \mathrm{kg}$, busulfan 14 $\mathrm{mg} / \mathrm{kg}$, etoposide $60 \mathrm{mg} / \mathrm{kg}$ ). However, Fujimaki et al. (2001) retrospectively analyzed the development of cardiac complications in patients who underwent allogeneic bone marrow transplantation (BMT) or PBSCT with the same regimen of cyclophosphamide $\left(2,250 \mathrm{mg} / \mathrm{m}^{2} /\right.$ day for consecutive days), thiotepa (200 mg/m $/ \mathrm{m}^{2}$ day for consecutive days), and total body irradiation, and found a significant correlation between LVEF before hematopoietic stem cell transplantation (HCT) and the development of cardiac complication. They recommended that patients with an LVEF less than $55 \%$ should received reduced-doses of the conditioning regimen to avoid cardiac toxicity.

Furthermore, high-dose cyclophosphamide (200 mg/kg divided into $50 \mathrm{mg} / \mathrm{kg}$ per day on days from -5 to -2 before the transplant) is usually used as the conditioning regimen for autoimmune diseases (Tyndall and Gatwohl 1997; Burt et al. 2003). Saccardi et al. (2004) reported that a direct causal association with cyclophosphamide was suspected in two of five cardiac deaths among 77 SSc patients who received auto-PBSCT in the EBMT database. Careful pre-transplant cardiac assessment is recommended in all SSc patients being considered for auto-PBSCT (Saccardi et al. 2004).

We considered that it was difficult to use conventional high-dose cyclophosphamide as the 
conditioning regimen in our patient because of cardiac dysfunction. We used an alkylating agent thiotepa, since, at a standard dose level (10-30 $\mathrm{mg} / \mathrm{m}^{2}$ ), the dose-limiting toxicity is myelosuppression, and other toxicities are infrequent (Wolff et al. 1990). We reduced the dose of cyclophosphamide $(50 \mathrm{mg} / \mathrm{kg} /$ day on days -3 and -2$)$ in combination with thiotepa $(10 \mathrm{mg} / \mathrm{kg}$ on day -5$)$ as described by Aversa et al. (1999). The posttransplant course was uneventful. The 1-year follow-up showed a good response with improvement of skin manifestations and immunological abnormalities. Recently, Giorgetti et al. (2004) also described successful autologous PBSCT using a conditioning regimen containing thiotepa in a patient with SSc and cardiac involvement. Therefore, thiotepa is suitable for a conditioning regimen of auto-PBSCT in patients with cardiac dysfunction including $\mathrm{SSc}$ in order to reduce cyclophosphamide-induced cardiotoxicity.

\section{Acknowledgments}

We thank Dr. A. Tyndall (University of Basel, Switzerland) and Dr. R. Saccardi (University of Florence, Italy) for helpful comments. This work was supported in part by a Grant-in-Aid (17590978) and the 21st Century COE Program from the Ministry of Education, Culture, Sports, Science and Technology of Japan, and a research grant (H15Nanchi-02) from the Ministry of Health and Welfare of Japan.

\section{References}

Aversa, F., Terenzi, A., Carotti, A., Flicini, R., Jacucci, R., Zei, T., Latini, P., Aristei, C., Santucci, A., Martelli, M.P., Cunningham, I., Reisner, Y. \& Martelli, M.F. (1999) Improved outcome with T-cell-depleted bone marrow transplantation for acute leukemia. J. Clin. Oncol., 17, $1545-1550$.

Burt, R.K., Oyama, Y., Traynor, A., Quigley, K., Brush, M., Rodriguez, J. \& Barr, W.G. (2003) Hematopoietic stem cell transplantation for systemic sclerosis with rapid improvement in skin scores: is neoangiogenesis occurring? Bone Marrow Transplant., 32, Suppl. 1, S65-S67.

Clements, P.J., Lachenbruch, P.A., Seibold, J.R., Zee, B., Steen, V.D., Brennan, P., Silman, A.J., Allegar, N., Varga, J. \& Massa, M. (1993) Skin thickness score in systemic sclerosis: an assessment of interobserver variability in 3 independent studies. J. Rheumatol., 20, 1892-1896.

Farge, D., Marolleau, J.P., Zohar,. S., Marjanovic, Z., Cabane, J., Mounier, N., Hachulla, E., Philippe, P., Sibilia, J., Rabian, C., Chevret, S. \& Gluckman, E. (2002) Autologous bone marrow transplantation in the treatment of refractory sys- temic sclerosis: early results from a French multicentre phase I-II study. Br. J. Haematol., 119, 726-739.

Farge, D., Passweg, J., van Laar, J.M., Marjanovic, Z., Besenthal, C., Finke, J., Peter, H.H., Breedveld, F.C., Fibbe, W.E., Black, C., Denton, C., Koetter, I., Locatelli, F., Martini, A., Schattenberg, A.V., van den Hoogen, F., van de Putte, L., Lanza, F., Arnold, R., Bacon, P.A., Bingham, S., Ciceri, F., Didier, B., Diez-Martin, J.L., Emery, P., Feremans, W., Hertenstein, B., Hiepe, F., Luosujarvi, R., Leon Lara, A., Marmont, A., Martinez, A.M., Pascual Cascon, H., Bocelli-Tyndall, C., Gluckman, E., Gratwohl, A. \& Tyndall, A. (2004) Autologous stem cell transplantation in the treatment of systemic sclerosis: report from the EBMT/EULAR Registry. Ann. Rheum. Dis., 63, 974-981.

Ferri, C., Valentini, G., Cozzi, F., Sebastiani, M., Michelassi, C., La Montagna, G., Bullo, A., Cazzato, M., Tirri, E., Storino, F., Giuggioli, D., Cuomo, G., Rosada, M., Bombardieri, S., Todesco, S. \& Tirri, G. (2002) Systemic sclerosis: demographic, clinical, and serologic features and survival in 1,012 Italian patients. Medicine, 81, 139-153.

Fujimaki, K., Maruta, A., Yoshida, M., Sakai, R., Tanabe, J., Koharazawa, H., Kodama, F., Asahina, S., Minamizawa, M., Matsuzaki, M., Fujisawa, S., Kanamori, H. \& Ishigatsubo, Y. (2001) Severe cardiac toxicity in hematological stem cell transplantation: predictive value of reduced left ventricular ejection fraction. Bone Marrow Transplant., 27, 307-310.

Gharib, M.I. \& Burnett, A.K. (2002) Chemotherapy-induced cardiotoxicity: current practice and prospects of prophylaxis. Eur. J. Heart Fail., 4, 235-242.

Giorgetti, F., Minnucci, M.L., Santori, P., Ercoli, L., Rossi, M., Del Papa, M., Morico, G., Squadroni, P., Olivieri, A. \& Centurioni, R. (2004) Autologous peripheral stem cell transplantation in a patient with diffuse systemic sclerosis: our experience. Reumatismo, 56, 51-56. (in Italian with English abstract)

Ioannidis, J.P., Vlachoyiannopoulos, P.G., Haidich, A.B., Medsger, T.A., Jr., Lucas, M., Michet, C.J., Kuwana, M., Yasuoka, H., van den Hoogen, F., Te Boome, L., van Laar, J.M., Verbeet, N.L., Matucci-Cerinic, M., Georgountzos, A. \& Moutsopoulos, H.M. (2002) Mortality in systemic sclerosis: an international meta-analysis of individual patient data. Am. J. Med., 118, 2-10.

Itoh, M., Iwai, K., Kotone-Miyahara, Y., Yamada, H., Ohno, H., Yamamoto, K., Tashima, M., Inoko, M., Nohara, R. \& Uchiyama, T. (2004) Successful allogeneic bone marrow transplantation for acute myelogenous leukemia after druginduced cardiomyopathy. Tohoku J. Exp. Med., 204, 85-91.

Janosik, D.L., Osborn, T.G., Moore, T.L., Shah, D.G., Kenney, R.G. \& Zuckner, J. (1989) Heart disease in systemic sclerosis. Semin. Arthritis. Rheum., 19, 191-200.

Kawabata, Y., Hirokawa, M., Komatsuda, A. \& Sawada, K. (2003) Clinical applications of CD34+ cell-selected peripheral blood stem cells. Ther. Apher. Dial., 7, 298-304.

McSweeney, P.A., Nash, R.A., Sullivan, K.M., Storek, J., Crofford, L.J., Dansey, R., Mayes, M.D., McDonagh, K.T., Nelson, J.L., Gooley, T.A., Holmberg, L.A., Chen, C.S., Wener, M.H., Ryan, K., Sunderhaus, J., Russell, K., Rambharose, J., Storb, R. \& Furst, D.E. (2002) High-dose immunosuppressive therapy for severe systemic sclerosis: initial outcomes. Blood, 100, 1602-1610.

Nishio, M., Nakao, S., Endo, T., Fujimoto, K., Takashima, H., Sakai, T., Bacigalupo, A., Koike, T. \& Sawada, K. (2001) Successful non-myeloablative stem cell transplantation for 
a heavily transfused woman with severe aplastic anemia complicated by heart failure. Bone Marrow Transplant., 28, 783-785.

Saccardi, R., Tyndall, A., Coghlan, G., Denton, C., Edan, G., Emdin, M., Farge, D., Fassas, A., Finke, J., Furst, D., Lassus, M., Mancardi, G., Miniati, I., Mini, E., Pagliai, F., Passweg, J., Pignone, A., van Laar, J.M., Bocelli-Tyndall, C. \& Matucci-Cerinic, M. (2004) Consensus statement concerning cardiotoxicity occurring during haematopoietic stem cell transplantation in the treatment of autoimmune diseases, with special reference to systemic sclerosis and multiple sclerosis. Bone Marrow Transplant., 34, 877-881.

Sakkas, L.I. \& Platsoucas, C.D. (2004) Is systemic sclerosis an antigen-driven T cell disease? Arthritis. Rheum., 50, 1721-1733.

Scussel-Lonzetti, L., Joyal, F., Raynauld, J.P., Roussin, A., Rich, E., Goulet, J.R., Raymond, Y. \& Senecal, J.L. (2002) Predicting mortality in systemic sclerosis: analysis of a cohort of 309 French Canadian patients with emphasis on features at diagnosis as predictive factors for survival. Medicine, 81, 154-167.

Subcommittee for scleroderma criteria of the American Rheumatism Association Diagnostic and Therapeutic Criteria Committee (1980) Preliminary criteria for the classification of systemic sclerosis (scleroderma). Arthritis.
Rheum., 23, 581-590.

Tang, W.H.W., Thomas, S., Kalaycio, M., Sobecks, R., Andresen, S., Jarvis, J., Rybicki, L., Pohlman, B., Francis, G.S. \& Bolwell, B.J. (2004) Clinical outcomes of patients with impaired left ventricular ejection fraction undergoing autologous bone marrow transplantation: can we safely transplant patients with impaired ejection fraction? Bone Marrow Transplant., 34, 603-607.

Tyndall, A. \& Gratwohl, A. (1997) Blood and marrow stem cell transplants in autoimmune disease. A consensus report written on behalf of the European League Against Rheumatism (EULAR) and the European Group for Blood and Marrow Transplantation (EBMT). Br. J. Pheumatol., 36, 390-392.

White, B., Moore, W.C., Wigley, F.M., Xiao, H.Q. \& Wise, R.A. (2000) Cyclophosphamide is associated with pulmonary function and survival benefit in patients with scleroderma and alveolitis. Ann. Intern. Med., 132, 947-954.

Wolff, S.N., Herzig, R.H., Fay, I.W., LeMaistre, C.F., Brown, R.A., Frei-Lahr, D., Stranjord, S., Giannone, L., Coccia, P. \& Weick, J.L. (1990) High-dose N, $\mathrm{N}^{\prime}, \mathrm{N}^{\prime \prime}$-triethylenethiophosphoramide (thiotepa) with autologous bone marrow transplantation: phase I studies. Semin. Oncol., 17, Suppl. $3,2-6$. 